\title{
ANÁLISE EMPÍRICA DO RETORNO DE LONGO PRAZO DAS AÇÕES DE EMPRESAS BRASILEIRAS EMISSORAS DE ADR
}

\section{EMPYRICAL ANALYSIS OF THE LONG-TERM RETURN OF AMERICAN DEPOSITARY RECEIPT (ADR) ISSUED BY BRAZILIAN ENTERPRISES}

\author{
Fernando Nascimento Oliveira \\ Banco Central do Brasil e IBMEC/RJ \\ fernando.nascimento@bcb.gov.br \\ Artur de Carvalho Delorme \\ IBMEC/RJ \\ tucadelorme@yahoo.com.br
}

Submissão: 02/09/2013

Aprovação: 01/08/2014

\section{RESUMO}

O presente estudo tem como objetivo analisar o impacto da dupla listagem sobre o comportamento das ações de empresas brasileiras. Para tal, foi analisada a performance de longo prazo por meio do método de Estudo de Eventos das ações de empresas brasileiras listadas na BM\&FBovespa S.A. - Bolsa de Valores Mercadorias e Futuros (BMFBovespa), emissoras de American Depositary Receipt (ADR), negociados no mercado norte-americano. O evento foi considerado como a data da primeira informação disponível ao mercado da intenção de adesão aos programas de ADR. Além da análise da presença de retornos anormais da amostra de forma consolidada, foram realizadas análises segregadas por Nível de ADR (Nível I, II ou III) e pelo período de ocorrência do evento (1992-1999 e 2000-2009). A população da pesquisa consiste em empresas brasileiras que aderiram aos programas de ADRs entre 1992 e 2009, totalizando 82 empresas na amostra. Nossos resultados mostram que a dupla listagem não proporcionou retornos acionários anormais às ações negociadas no mercado brasileiro.

Palavras-chave: American Depositary Receipt. ADR; Estudo de Eventos. Retorno Anormal. 


\begin{abstract}
The present study aims to analyze the impact of cross listing upon the Brazilian stocks' behavior. Therefore, it was analyzed the long-term performance (36 months) by a Event Study method of Brazilian companies listed on the BMFBovespa, that have issued American Depositary Receipt (ADR) negotiated in the U.S. market. The event was considered as of the date of the first information available to the market on the intention to adhere to ADR Programs. Besides analyzing the presence of abnormal returns on a consolidated sample, the same analysis was developed considering the differences between the ADRs levels (Level I, II or III) and between the event's occurrence period (1992-1999 and 2000-2009). The research population consists of Brazilian companies that joined the cross listing programs through ADRs between 1992 and 2009, with a sample of 82 companies. Our results show that the cross listing has not provided abnormal returns to stocks negotiated in the Brazilian market.
\end{abstract}

Keywords: American Depositary Receipt. ADR; Event Study. Abnormal Return. 
1 Introdução

Apesar de a globalização ser um fenômeno complexo, abrangendo múltiplas dimensões, normalmente os aspectos econômicos são aqueles mais visíveis e determinantes, em decorrência do processo de internacionalização do capital verificado nas últimas décadas. ${ }^{1}$

Corazza (2005) considera que o processo de globalização financeira, desconhece fronteiras e poderes nacionais, na medida em que perderam suas referências espaciais, assumindo a forma de fluxos financeiros "desterritorializados".

O constante processo de integração dos mercados aumenta o número de empresas que buscam acessar novas fontes de capital para financiar seu crescimento, reduzindo riscos e, principalmente, o custo de capital. Neste sentido, uma das principais formas de ampliar a disponibilidade de recursos e expandir as fontes de financiamento das empresas de capital aberto se dá por meio da listagem dos seus títulos em mais de um mercado (dupla listagem).

Destaca-se o mercado norte-americano como principal receptor de empresas estrangeiras que visam aderir aos programas de dupla listagem, por meio de American Depositary Receipts (ADRs). Apesar da longa existência, as empresas brasileiras iniciaram a utilização destes somente no início da década de 1990, quando a Comissão de Valores Mobiliários (CVM) possibilitou às empresas de capital aberto negociar suas ações em outros mercados, com o objetivo de alavancar o mercado de capitais brasileiro (GARCIA; GUSMÃO, 2008).

Com o desenvolvimento do mercado de capitais brasileiro e o elevado nível de integração junto aos mercados internacionais, torna cada vez complicado para os investidores domésticos registrar ganhos anormais em suas carteiras de investimentos.

Neste contexto, o presente estudo tem como objetivo analisar o impacto da dupla listagem sobre o comportamento de longo prazo das ações de empresas brasileiras. Para tal, será analisado o desempenho de longo prazo por meio do método de Estudo de Eventos das ações de empresas brasileiras listadas na BMFBovespa, emissoras de ADRs. Especificamente, visa analisar se a adesão aos programas de dupla listagem produz retorno acionário anormal no longo prazo (36 meses) para os investidores domésticos. Além disso, foi verificada a existência de retornos anormais de forma segredada entre os diferentes níveis de ADR (Nível I, II e III) e pelo período de ocorrência do evento (1992-1999 e 2000-2009).

\footnotetext{
${ }^{1}$ Ver Faria (2004) e Furmann (2011).
} 
O evento, utilizado como base metodológica deste estudo, foi a data da primeira informação disponível ao mercado da intenção de adesão aos programas de ADR, considerando uma janela de 36 meses antes e depois do evento. Dentre as diferentes formas de informação utilizadas como data do evento, considerou-se a primeira disponível ao mercado, dentre as seguintes: (i) aprovação pelo Conselho de Administração do lançamento do programa; (ii) inscrição prévia para análise da CVM; ou (iii) aprovação pela CVM da adesão ao programa de ADRs.

Camargos e Barbosa (2007), por meio de um Estudo de Eventos, analisaram se a dupla listagem gerou valorização das ações negociadas no mercado doméstico de 34 empresas brasileiras que aderiram aos programas de ADR (Nível I, II e III) no período de 1992 a 2002. Enquanto Silva (2010) investigou também a partir da mesma metodologia, se a listagem de ADRs de 37 empresas brasileiras na NYSE (Nível II e III) produziu retornos anormais em um período de 24 meses após a listagem. Foi sugerido por Silva (2010) que a data de divulgação da intenção de adesão aos programas de ADR, como data do evento, talvez pudesse gerar resultados distintos do verificado.

Com relação aos referidos estudos, buscou-se como diferencial a ampliação da população da pesquisa, com a inclusão das ações do Nível I, negociados em mercado de balcão, bem como a manutenção das ações com indisponibilidade de dados históricos em período anterior ao evento, utilizando o mês do evento como $\mathrm{t}_{0}$. Além disso, conforme sugerido por Silva (2010), utilizou-se a data de divulgação da intenção ao mercado como data do evento, para todas as empresas que em algum momento tiveram ações listadas no mercado norte-americano, no período entre 1992 e 2009, com no mínimo 36 meses de negociação e razoável liquidez. A população da pesquisa consiste então, de empresas brasileiras que aderiram aos programas de dupla listagem, por meio de ADRs, totalizando 82 empresas na amostra, sendo 49 do Nível I, 22 do Nível II e 11 do Nível III.

Entre os resultados aqui encontrados, no que se refere à análise do retorno acionário anormal no longo prazo da amostra consolidada, objetivo central do estudo, não foi encontrada significância estatística para o período de 36 meses. Ou seja, não se pode rejeitar a hipótese nula, constatando-se que a dupla listagem não proporcionou retornos acionários anormais e, por conseguinte, não teve nenhum efeito para os acionistas no mercado brasileiro. Em relação aos resultados das amostras de forma segregada, nota-se divergência dos resultados entre os diferentes níveis de ADR (I, II e III) e entre os diferentes períodos de ocorrência dos eventos (1992 a 1999 e 2000 a 2009). 
Este trabalho contém ainda outras seções, além da introdução. A segunda seção fará a descrição da metodologia de pesquisa proposta para o estudo, com as respectivas razões e o processo de seleção da amostra. A terceira seção elucidará os resultados da pesquisa e, finalmente, na quarta seção concluiremos.

\section{Metodologia}

Neste artigo, buscamos verificar se a adesão aos programas de ADRs do tipo I, II e III gerou retornos anormais às ações negociadas na BMFBovespa, por meio de um Estudo de Eventos.

Os ADRs do tipo I se caracterizam por: não precisar atender a normas contábeis americanas; serem negociados no mercado de balcão e por não ser um lançamento de novas ações. Além disso, é o programa mais simples, pois não precisa atender a todas as exigências da Securities Exchange Commission - SEC (a CVM norte-americana).

Ao contrário dos ADRs do tipo I, os ADRs de tipo II e III são mais complexos. Os ADRs do tipo II devem atender às normas contábeis norte-americanas, e não se caracterizam por lançamento de novas ações. Devem respeitar maiores exigências da SEC, por ser obrigatório o registro do ADR na Bolsa de Valores.

Os ADRs do tipo III são os mais onerosos. Eles devem atender aos requisitos da SEC além das atender a normas contábeis norte-americanas. Eles têm como objetivo o levantamento de recursos para a empresa e seu programa de divulgação institucional deve ser de alta qualidade.

Um estudo de eventos é um método estatístico para avaliar o impacto de um evento sobre o valor de uma empresa. A ideia básica é encontrar o retorno anormal atribuível ao evento que está sendo estudado por ajuste para o retorno que resulta da flutuação de preços do mercado como um todo. Como a metodologia do evento pode ser usada para obter os efeitos de qualquer tipo de evento na direção e magnitude das variações de preços de ações, é muito versátil. Estudos de eventos são, portanto, comuns a várias áreas de pesquisa, como contabilidade, finanças e economia entre muitas outras.

Analisamos o impacto da adesão aos programas de dupla listagem sobre o retorno das ações de forma segregada por Nível de ADR (I, II e III), bem como pelo período de ocorrência do evento (1992-1999 e 2000-2009). 
O evento, utilizado com base metodológica deste estudo, foi a data da primeira informação disponível ao mercado da intenção de adesão aos programas de ADR. Entre as diferentes formas de informação utilizadas como data do evento, foi considerada a primeira disponível ao mercado, entre as seguintes: (i) aprovação pelo Conselho de Administração da empresa do lançamento do programa; (ii) inscrição prévia para análise da CVM; ou (iii) aprovação pela CVM da adesão ao programa de ADR.

\subsection{Estabelecimento das hipóteses}

O par de hipóteses centrais deste estudo visa analisar a questão da eficiência dos mercados e da existência de retornos anormais com base em um Estudo de Eventos que estuda a adesão ao programa de ADRs. A hipótese nula e alternativa será apresentada como:

$\mathrm{H}_{0}$ - Os retornos anormais dos preços das ações de empresas emissoras de ADRs após o primeiro anúncio ao mercado do interesse na adesão ao programa são iguais a 0 (zero);

$\mathrm{H}_{1}$ - Os retornos anormais dos preços das ações de empresas emissoras de ADRs após o primeiro anúncio ao mercado do interesse na adesão ao programa são diferentes de 0 (zero).

\subsection{Definição da amostra e do método}

Neste trabalho, como forma de cálculo do retorno observado das ações, utilizou-se a capitalização contínua em detrimento da capitalização discreta, considerando que a forma logarítmica, segundo Soares, Rostagno e Soares (2002), contribui para uma melhor aderência à distribuição normal dos retornos, o que é refletido nos testes estatísticos paramétricos. A forma logarítmica para os retornos é dada pela equação (1) abaixo:

$$
R_{i t}=\operatorname{Ln}\left(\frac{P_{i t}}{P_{i, t-1}}\right)
$$

As cotações das ações i são mensais em $t$, por meio das quais é possível verificar a taxa de retorno mensal, observando $\left(\mathrm{R}_{\mathrm{it}}\right)$, que é equivalente ao retorno normal da razão entre o preço de fechamento $\left(\mathrm{P}_{\mathrm{it}}\right)$ e o preço de fechamento na data $\mathrm{t}-1\left(\mathrm{P}_{\mathrm{i}, \mathrm{t}-1}\right)$. 
Os Retornos Anormais (RA) são utilizados para avaliar o impacto de um evento sobre o preço de uma ação, com base na estimativa de retorno da ação após todos os ganhos terem sido incorporados ao seu valor durante o período do evento, em comparação com o valor em caso de não ocorrência do evento (retorno normal ou retorno esperado) (SETH, 1990). Neste sentido, o retorno anormal é dado pelo retorno real ex-post do título, subtraindo o retorno normal esperado. O retorno anormal é dado então pela seguinte fórmula:

$R A_{i t}=R_{i t}-E\left(R_{i t}\right)$

onde $\mathrm{RA}_{\mathrm{it}}$, é o retorno anormal, $\mathrm{R}_{\mathrm{it}}$,é o retorno atual e $\mathrm{E}\left(\mathrm{R}_{\mathrm{it}}\right)$ é o retorno esperado (normal) da ação ${ }_{\mathrm{i}}$ no período de tempo .

A fórmula de cálculo do retorno anormal utilizou o Modelo de Mercado, considerando o IBrX como proxy para apuração do retorno esperado, de acordo com Bruni (2002). ${ }^{2}$ Desta forma, os retornos anormais foram calculados como os retornos das ações ajustados pelo retorno de mercado, da seguinte maneira:

$R A_{\mathrm{i}, t}=R_{i, t}-R_{\text {mercado }, t}$

Calculados os retornos anormais, estes foram acumulados (somados) individualmente dependendo da data do evento, pela técnica do Retorno Anormal Acumulado (RAA), em cada um dos meses relativos para todas as empresas, para então dar continuidade aos testes estatísticos segundo Mackinlay (1997). Os retornos foram acumulados pelas ações, equação (4), e no tempo equação (5):

$R A A_{i t}=\sum_{t=1}^{n} R A_{i t}$

(4)

$\overline{R A A}_{t(t 1, t 2)}=\frac{1}{N} \sum_{i=1}^{n} R A A_{i(t 1, t 2)}$

\footnotetext{
${ }^{2}$ Em função da metodologia empregada na composição do Ibovespa, de ponderação baseada na liquidez das ações, o mesmo acaba apresentando relevante concentração em poucos ativos. Por outro lado, o IBrX representa uma carteira teórica com as 100 empresas melhor classificadas em relação ao seu índice de negociabilidade, apurado nos 12 meses anteriores e seu critério de ponderação considera o número de ações de cada empresa disponível à negociação do mercado (BOVESPA, 1997). No período de 1992 a 2001, foi utilizado o IBA (Índice Brasileiro de Ações), mensurado com metodologia similar ao IBrX.
} 
Onde $\mathrm{RAA}_{i t}$ é o retorno anormal acumulado da empresa i no período $t ; \mathrm{RA}_{i t}$ é o retorno anormal para determinada empresa ${ }_{i}$ no período t; n é o número de empresas; RAA $_{\mathrm{t}(\mathrm{t} 1, \mathrm{t} 2)}$ é a média do RAA para todas as empresas no período $\mathrm{t}$ entre as janelas ${ }_{\mathrm{t} 1} \mathrm{e}_{\mathrm{t} 2}$.

Inicialmente, o objetivo era utilizar todas as empresas brasileiras que tivessem aderido aos programas de ADR, dos níveis I, II e III, até 31 de dezembro de 2009, em função do horizonte da janela pós-evento, com histórico de negociação no período de 3 anos (36 meses) antes e após a adesão, ou seja, apenas empresas com informações disponíveis para a totalidade da janela de estimação e janela pós-evento. Entretanto, a indisponibilidade de dados históricos com base nestes critérios, em função da abertura de capital (IPO - Initial Public Offering) em data inferior ao período da janela de estimação, restringia de forma significativa o universo da amostra, reduzindo de 82 para apenas 38 empresas.

Com o intuito de adequar a amostra, a janela do evento foi alterada, sendo composta por um período de 36 meses após a data do evento, além do primeiro mês da ocorrência do evento, totalizando 37 meses. Foram também incorporadas ações de empresas recém-abertas, ou com data do evento similar à primeira informação histórica disponível. Desta forma, a amostra abrangeu todas as empresas brasileiras listadas na BMFBovespa que aderiram aos programas de ADR nos níveis I, II e III, até o limite de tempo de 21 de dezembro de 2009, independente de estar listada naquele momento, porém com histórico de no mínimo 37 meses.

Para as empresas do setor de telefonia pós-privatização da Telebrás, além da ALL, Banco Santander, Contax, Cosan, CPFL, Cyrela CP, Gol, LLX, Rossi e Ultrapar, a data do primeiro dia de informação disponível é inferior a um mês da data do evento. Para estes casos, calculou-se o retorno das ações no mês zero pela diferença entre o valor no último dia do mês da listagem e o valor negociado no primeiro dia disponível.

Para empresas com mais de um programa de ADR foi considerada a primeira adesão como data de evento. Nos casos em que as empresas contêm duas classes de ações (ordinárias e preferencias) e ambas possuam ADRs, foram utilizadas as ações com maior liquidez, o que corresponde às ações preferenciais no mercado brasileiro. Empresas com mais de 20 dias sem negociação foram excluídas da amostra em função da baixa liquidez.

Os dados relativos às datas dos eventos foram coletados no website da CVM, da BMFBovespa e de relações com investidores das respectivas empresas. Os retornos das ações e do $\mathrm{IBrX}$ foram obtidos no banco de dados Economática. No cálculo dos retornos das ações, 
PUC Minas E\&G - REVISTA ECONOMIA E GESTÃO

ISSN 1984-6606

foram utilizadas cotações de fechamento mensais, em Real, ajustadas por proventos, inclusive

dividendos, para evitar que tais eventos influenciassem os resultados. A amostra final foi

formada então por 82 empresas, sendo 49 do Nível I, 22 do Nível II e 11 no Nível III:

Tabela 1 - Programas de ADR da Amostra Completa

\begin{tabular}{|c|c|c|c|c|c|c|c|}
\hline Nome & Código & Nível & Data do Evento & Nome & Código & Nível & Data do Evento \\
\hline Acesita & ACES4 & I & $04 / 07 / 1994$ & Light & LIGT3 & I & $17 / 11 / 2008$ \\
\hline AES Tietê & GETI4 & I & 03/09/1999 & LLX & LLXL3 & I & $31 / 07 / 2008$ \\
\hline ALL & ALLL11 & I & $30 / 03 / 2005$ & Lojas Americanas & LAME4 & I & $22 / 05 / 1995$ \\
\hline Alpargatas & ALPA4 & I & 07/04/1994 & Lupatech & LUPA3 & I & $16 / 11 / 2009$ \\
\hline Ambev & AMBV4 & II & $15 / 07 / 1996$ & Marcopolo & POMO4 & I & 28/08/1996 \\
\hline AMIL & AMIL3 & I & $17 / 06 / 2009$ & MMX & MMXM3 & I & $05 / 02 / 2007$ \\
\hline Aracruz & ARCZ6 & III & $26 / 05 / 1992$ & MPX & MPXE3 & I & 08/05/2009 \\
\hline Banco do Brasil & BBAS3 & I & $02 / 12 / 2009$ & MRV & MRVE3 & I & 27/03/2009 \\
\hline Belgo Mineira & ARCE3 & I & 21/11/1995 & OGX & OGXP3 & I & 08/05/2009 \\
\hline Bombril & BOBR4 & I & $24 / 05 / 1994$ & Pão de Açúcar & PCAR4 & III & $28 / 05 / 1997$ \\
\hline BR Dis tribuidora & BRDT4 & I & $20 / 06 / 1995$ & Paraná Banco & PRBC4 & I & $19 / 08 / 2008$ \\
\hline BR Malls & BRML3 & I & $24 / 12 / 2008$ & PDG & PDGR3 & I & $08 / 12 / 2008$ \\
\hline Bradesco & BBDC4 & II & 09/06/1997 & Perdigão & PRGA4 & I & $25 / 09 / 1996$ \\
\hline Brasil Telecom & BRTP4 & II & $21 / 09 / 1998$ & Petrobras & PETR4 & II & $12 / 11 / 1996$ \\
\hline Braskem & BRKM5 & II & $21 / 12 / 1998$ & Rossi & RSID3 & I & $15 / 07 / 1997$ \\
\hline Cataguazes & FLCL5 & I & $21 / 02 / 2002$ & Sabesp & SBSP3 & III & 09/05/2002 \\
\hline Celesc & CLSC4 & I & 05/09/1994 & Sadia & SDIA4 & II & $10 / 04 / 2001$ \\
\hline Cemig & CMIG4 & I & $26 / 05 / 1993$ & Santander & SANB11 & III & 07/10/2009 \\
\hline Cesp & CESP5 & I & 01/02/1994 & Saraiva & SLED4 & I & $21 / 09 / 2000$ \\
\hline Contax & CTAX4 & I & $31 / 08 / 2005$ & Sid Tubarão & CSTB4 & III & 28/09/1999 \\
\hline Copel & CPLE3 & I & 03/04/1996 & Suzano Papel e Celulose & SUZB5 & I & $10 / 11 / 1993$ \\
\hline Cosan & CZLT11 & II & $16 / 08 / 2007$ & Suzano Petroquímica & SZPQ4 & I & $02 / 07 / 2002$ \\
\hline CPFL & CPFE3 & III & $29 / 09 / 2004$ & TAM & TAMM4 & III & $10 / 03 / 2006$ \\
\hline CR2 & CRDE3 & I & 09/02/2009 & TEKA & TEKA4 & I & 27/01/1994 \\
\hline CSN & CSNA3 & II & $29 / 10 / 1993$ & Tele Centro Oeste & TCOC4 & II & 21/09/1998 \\
\hline Cyrela & CYRE3 & I & 20/9/2005 & Tele Leste Cel & TLCP4 & II & 21/09/1998 \\
\hline Cyrela CP & CCPR3 & I & $14 / 08 / 2007$ & Tele NECel & TNEP4 & II & 21/09/1998 \\
\hline Daycoval & DAYC4 & I & $14 / 08 / 2008$ & Tele SE Cel & TSEP4 & II & 21/09/1998 \\
\hline Electrolux & REPA4 & I & $30 / 06 / 1994$ & Telebrás & TELB4 & I & $20 / 07 / 1992$ \\
\hline Eletrobras & ELET6 & II & 05/01/1994 & Telemar & TNLP4 & II & $21 / 09 / 1998$ \\
\hline Embraer & EMBR4 & III & $21 / 07 / 2000$ & Telemig & TMCP4 & II & $21 / 09 / 1998$ \\
\hline Embratel & EBTP4 & II & $21 / 09 / 1998$ & TIM & TCSL4 & II & $21 / 09 / 1998$ \\
\hline Equatorial & EQTL3 & I & $04 / 06 / 2009$ & TPI & TPIS3 & I & $23 / 12 / 2008$ \\
\hline Gafisa & GFSA3 & III & $16 / 03 / 2007$ & Tractebel & TBLE3 & I & $27 / 06 / 2002$ \\
\hline Ger Paranapanema & GEPA4 & I & $24 / 09 / 1999$ & Trans Paulista & TRPL4 & I & 03/09/1999 \\
\hline Gerdau & GGBR4 & II & $10 / 03 / 1999$ & Ultrapar & UGPA4 & III & 28/09/1999 \\
\hline GOL & GOLL4 & III & $24 / 06 / 2004$ & Usiminas & USIM5 & I & $16 / 09 / 1994$ \\
\hline Iochpe-Maxion & MYPK4 & I & $04 / 05 / 1994$ & VALE & VALE5 & II & $17 / 02 / 1994$ \\
\hline Itau-Unibanco & ITUB4 & II & $21 / 02 / 2002$ & Via Varejo & GLOB4 & I & $20 / 02 / 1997$ \\
\hline JBS & JBSS3 & I & $01 / 12 / 2008$ & VIVO & VIVO4 & II & 21/09/1998 \\
\hline Klabin & KLBN4 & $\mathrm{I}$ & 07/11/1994 & Votorantim & VCPA4 & II & $17 / 06 / 1992$ \\
\hline
\end{tabular}

Fonte: Elaborada pelo autor. 
Um grupo relevante de empresas não possuía dados históricos suficientes no período da janela de estimação, impossibilitando regressões para obtenção de parâmetros de estimação. De acordo com Bruni (2002), em função da baixa liquidez dos ativos e do horizonte relativamente curto dos dados disponíveis, pode-se utilizar um modelo alternativo, com ajuste ao modelo de mercado, em que o retorno anormal pode ser considerado como aquele superior ao de um portfólio de mercado. Foi utilizado então, conforme Ritter (1991), o modelo ajustado de mercado onde alfa é igual a 0 e beta é igual a 1 . Desta forma, o cálculo do retorno anormal foi encontrado com base no verificado na expressão (2), em que o retorno esperado é o próprio retorno de mercado (IBrX).

$R A_{\mathrm{i}, t}=R_{i, t}-R_{\text {mercado }, t}$

Brown e Warner (1985) consideram que não há melhorias relevantes com a utilização de metodologias sofisticadas. Paralelamente, Kloeckner (1995) sugere que a adoção de um modelo mais simples para a geração dos retornos anormais não acarreta em prejuízos aos resultados dos estudos de eventos. ${ }^{34}$

Foram realizados testes paramétricos de Student (teste $t$ ) para testar as hipóteses, com nível de significância de 5\% ( $p$-value $<\alpha$, sendo $\alpha=0,05$ ). Isso quer dizer que se rejeita $\mathrm{H}_{0}$ quando o valor calculado ( $p$-value) for menor que o valor de $\alpha$, o que possibilitaria entender que a média dos retornos é diferente de zero. Caso fossem constatados retornos anormais significativos e diferentes de zero durante o evento, com rejeição da $\mathrm{H}_{0}$, seria possível concluir pela não existência da hipótese de eficiência semiforte do mercado, em função da não incorporação do efeito do anúncio da adesão aos programas de ADR sobre os preços das ações analisadas.

A preparação dos dados e cálculo dos retornos anormais foi realizada no software Microsoft Excel, versão 2010. Os testes estatísticos foram efetuados utilizando-se o software STATA - Data Analysis and Statistical Software, versão 12.

\footnotetext{
${ }^{3}$ Uma alternativa seria utilizar o Arbitrage Pricing Theory (APT). O APT é um modelo de equilíbrio geral. Na Literatura, ele é conhecido como modelo de vários índices ou vários fatores. Estes são choques macroeconômicos não esperados, isto é, diferença entre valores observados e valores esperados de variáveis macroeconômicas. Para Mackinlay (1997), o principal ganho potencial de utilizar o modelo APT é de eliminar os vieses introduzidos pelo Capital Asset Pricing Model, CAPM.

${ }^{4}$ Ver Khotari e Warner (2006) e Soares, Rostagno e Soares (2002) para análises mais recente sobre a relação entre estudos de eventos e modelos mais simples de retornos anormais.
} 


\section{Resultados}

O presente item apresenta os resultados obtidos por meio do Estudo de Eventos realizado sobre as empresas brasileiras após adesão aos programas de ADR no mercado norteamericano.

A apresentação dos resultados do estudo está dividida em seis seções. $\mathrm{Na}$ primeira, e principal seção, avalia-se o resultado do estudo sobre a amostra completa. Posteriormente, os resultados foram segregados e analisados dentre os três diferentes Níveis de ADR (I, II e III). Além disso, os resultados também foram segregados e analisados pelo período de ocorrência do evento (1992-1999 e de 2000-2009).

\subsection{Amostra completa}

Conforme ressaltado anteriormente, foi compilada a primeira adesão aos níveis I, II ou III, de todas as empresas brasileiras no período de 1992 a 2009. Após as exclusões de empresas por indisponibilidade de dados ou baixa liquidez, seguindo os critérios definidos, a amostra completa totalizou 82 empresas.

A Tabela 2 apresenta a análise da estatística descritiva da amostra completa, composta pelas empresas do Nível I, II e III (82 empresas), com informações sobre a média, a mediana e o desvio padrão do Retorno Anormal Logarítmico.

Nota-se que a média mensal do RA logarítmico não apresenta um comportamento uniforme. A média dos retornos anormais apresentou-se negativa em 19 dos 37 períodos, ou seja, abaixo do retorno do $\mathrm{IBrX}$ (retorno esperado ou retorno de mercado). O maior retorno anormal médio foi verificado no mês $2(+3,9 \%)$, enquanto no mês 19 o retorno anormal ficou em $-3,6 \%$, o menor da amostra. O patamar do desvio padrão manteve certa regularidade, oscilando entre $19,3 \%$ no mês 2 e $10,1 \%$ no mês 33 . 


\begin{tabular}{l|c|c|c|c|c}
\hline Mês & Média & Mediana & Desvio Padrão & Mínimo & Máximo \\
\hline Mês 0 & $-0,3 \%$ & $-1,0 \%$ & $15,3 \%$ & $-41,1 \%$ & $75,2 \%$ \\
Mês 1 & $1,4 \%$ & $1,2 \%$ & $14,3 \%$ & $-35,3 \%$ & $42,6 \%$ \\
Mês 2 & $3,9 \%$ & $3,1 \%$ & $19,4 \%$ & $-54,1 \%$ & $57,5 \%$ \\
Mês 3 & $-1,0 \%$ & $-1,6 \%$ & $12,1 \%$ & $-53,4 \%$ & $34,2 \%$ \\
Mês 4 & $1,4 \%$ & $-0,3 \%$ & $13,5 \%$ & $-44,3 \%$ & $38,1 \%$ \\
Mês 5 & $3,4 \%$ & $3,0 \%$ & $12,9 \%$ & $-28,8 \%$ & $49,1 \%$ \\
Mês 6 & $1,2 \%$ & $-1,2 \%$ & $13,9 \%$ & $-35,0 \%$ & $44,8 \%$ \\
Mês 7 & $0,9 \%$ & $0,4 \%$ & $12,5 \%$ & $-21,5 \%$ & $48,9 \%$ \\
Mês 8 & $0,5 \%$ & $-0,8 \%$ & $10,4 \%$ & $-19,7 \%$ & $35,8 \%$ \\
Mês 9 & $0,5 \%$ & $2,0 \%$ & $12,3 \%$ & $-50,7 \%$ & $26,1 \%$ \\
Mês 10 & $1,0 \%$ & $0,3 \%$ & $11,1 \%$ & $-21,9 \%$ & $44,8 \%$ \\
Mês 11 & $1,9 \%$ & $3,2 \%$ & $10,8 \%$ & $-29,3 \%$ & $27,7 \%$ \\
Mês 12 & $-1,3 \%$ & $-2,1 \%$ & $11,2 \%$ & $-36,1 \%$ & $35,9 \%$ \\
Mês 13 & $-0,5 \%$ & $-0,3 \%$ & $11,0 \%$ & $-25,5 \%$ & $58,0 \%$ \\
Mês 14 & $-1,9 \%$ & $-0,4 \%$ & $13,6 \%$ & $-67,5 \%$ & $23,8 \%$ \\
Mês 15 & $-2,3 \%$ & $-1,8 \%$ & $18,9 \%$ & $-114,4 \%$ & $38,0 \%$ \\
Mês 16 & $0,9 \%$ & $-0,5 \%$ & $10,8 \%$ & $-28,3 \%$ & $36,0 \%$ \\
Mês 17 & $2,6 \%$ & $1,0 \%$ & $12,0 \%$ & $-30,0 \%$ & $36,7 \%$ \\
Mês 18 & $0,5 \%$ & $1,1 \%$ & $13,1 \%$ & $-64,5 \%$ & $40,2 \%$ \\
Mês 19 & $-3,6 \%$ & $-2,3 \%$ & $15,8 \%$ & $-65,0 \%$ & $46,8 \%$ \\
Mês 20 & $-1,1 \%$ & $2,0 \%$ & $13,7 \%$ & $-53,2 \%$ & $27,8 \%$ \\
Mês 21 & $0,2 \%$ & $2,5 \%$ & $14,0 \%$ & $-46,6 \%$ & $37,6 \%$ \\
Mês 22 & $-0,8 \%$ & $0,4 \%$ & $11,8 \%$ & $-44,1 \%$ & $24,3 \%$ \\
Mês 23 & $0,4 \%$ & $0,3 \%$ & $11,5 \%$ & $-37,4 \%$ & $39,8 \%$ \\
Mês 24 & $-1,6 \%$ & $-1,7 \%$ & $14,4 \%$ & $-53,8 \%$ & $32,9 \%$ \\
Mês 25 & $-0,2 \%$ & $-0,5 \%$ & $11,2 \%$ & $-27,0 \%$ & $38,9 \%$ \\
Mês 26 & $-3,1 \%$ & $-2,8 \%$ & $11,9 \%$ & $-34,4 \%$ & $57,1 \%$ \\
Mês 27 & $2,0 \%$ & $1,9 \%$ & $12,1 \%$ & $-23,2 \%$ & $43,6 \%$ \\
Mês 28 & $0,5 \%$ & $-1,0 \%$ & $11,2 \%$ & $-20,5 \%$ & $32,9 \%$ \\
Mês 29 & $-1,6 \%$ & $0,4 \%$ & $11,5 \%$ & $-56,6 \%$ & $19,5 \%$ \\
Mês 30 & $-1,8 \%$ & $-1,9 \%$ & $11,4 \%$ & $-28,6 \%$ & $22,9 \%$ \\
Mês 31 & $-0,7 \%$ & $0,9 \%$ & $12,6 \%$ & $-47,8 \%$ & $26,9 \%$ \\
Mês 32 & $-0,5 \%$ & $-0,9 \%$ & $11,0 \%$ & $-37,1 \%$ & $25,9 \%$ \\
Mês 33 & $0,9 \%$ & $-1,3 \%$ & $12,0 \%$ & $-31,6 \%$ & $40,6 \%$ \\
Mês 34 & $-0,4 \%$ & $-0,2 \%$ & $10,1 \%$ & $-23,9 \%$ & $26,7 \%$ \\
Mês 35 & $-1,8 \%$ & $-2,5 \%$ & $11,5 \%$ & $-24,7 \%$ & $37,9 \%$ \\
Mês 36 & $-2,6 \%$ & $-0,9 \%$ & $14,6 \%$ & $-65,9 \%$ & $23,9 \%$ \\
\hline
\end{tabular}

Fonte: Elaborada pelo autor.

Na Figura 1, ilustra-se a média do retorno anormal mensal nos 37 períodos, na amostra composta por 82 empresas, com a média do RA oscilando ao redor de zero, com picos nos meses 2, 5, 17 e 27 . 
Figura 1 - Média do RA Logarítmico (Amostra Completa)

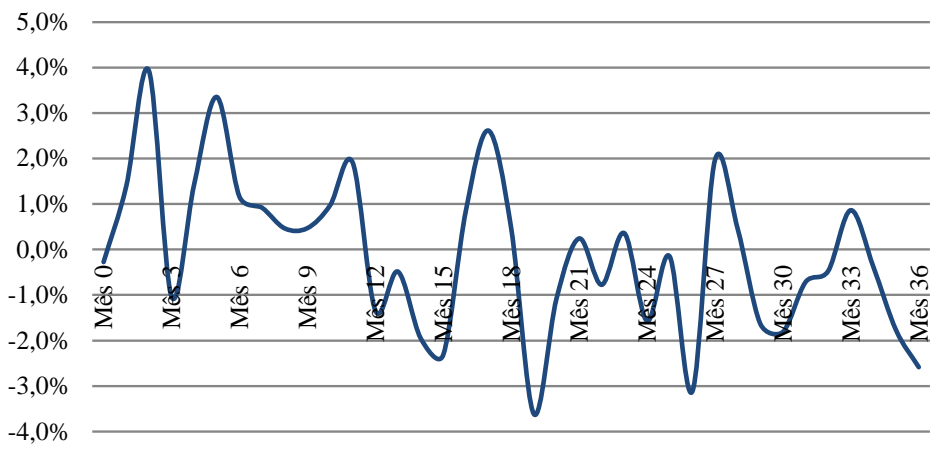

Fonte: Elaborada pelo autor.

Na Tabela 3, analisou-se a estatística descritiva do RAA da amostra completa. Com base no resultado verificado, nota-se que o RAA ficou negativo em 3,3\%, o que implicaria a conclusão de retorno anormal negativo após 36 meses da adesão aos programas de ADR. O desvio padrão ficou extremamente elevado, em 80,6\%. 
E\&G - REVISTA ECONOMIA E GESTÃO

ISSN 1984-6606

Tabela 3 - RAA da Amostra Completa (Estatística Descritiva)

\begin{tabular}{c|c|c|c|c|c}
\hline Mês & Média & Mediana & Desvio Padrão & Mínimo & Máximo \\
\hline Mês 0 & $-0,3 \%$ & $-1,0 \%$ & $15,3 \%$ & $-41,1 \%$ & $75,2 \%$ \\
Mês 1 & $1,1 \%$ & $-2,5 \%$ & $19,2 \%$ & $-42,5 \%$ & $73,6 \%$ \\
Mês 2 & $5,0 \%$ & $2,8 \%$ & $28,5 \%$ & $-74,1 \%$ & $127,7 \%$ \\
Mês 3 & $4,0 \%$ & $0,8 \%$ & $30,6 \%$ & $-126,4 \%$ & $111,9 \%$ \\
Mês 4 & $5,4 \%$ & $2,9 \%$ & $33,6 \%$ & $-88,3 \%$ & $122,4 \%$ \\
Mês 5 & $8,8 \%$ & $7,4 \%$ & $37,3 \%$ & $-83,2 \%$ & $135,0 \%$ \\
Mês 6 & $10,0 \%$ & $11,3 \%$ & $38,1 \%$ & $-104,2 \%$ & $142,6 \%$ \\
Mês 7 & $10,9 \%$ & $10,1 \%$ & $36,2 \%$ & $-86,7 \%$ & $128,0 \%$ \\
Mês 8 & $11,3 \%$ & $10,1 \%$ & $38,4 \%$ & $-66,7 \%$ & $138,5 \%$ \\
Mês 9 & $11,8 \%$ & $8,7 \%$ & $41,2 \%$ & $-108,9 \%$ & $133,4 \%$ \\
Mês 10 & $12,8 \%$ & $9,8 \%$ & $41,0 \%$ & $-129,8 \%$ & $139,7 \%$ \\
Mês 11 & $14,7 \%$ & $10,6 \%$ & $41,5 \%$ & $-112,0 \%$ & $136,0 \%$ \\
Mês 12 & $13,3 \%$ & $9,9 \%$ & $42,8 \%$ & $-98,8 \%$ & $136,9 \%$ \\
Mês 13 & $12,9 \%$ & $8,0 \%$ & $41,1 \%$ & $-91,7 \%$ & $135,0 \%$ \\
Mês 14 & $10,9 \%$ & $9,7 \%$ & $43,0 \%$ & $-88,1 \%$ & $135,2 \%$ \\
Mês 15 & $8,6 \%$ & $11,5 \%$ & $52,0 \%$ & $-193,2 \%$ & $153,1 \%$ \\
Mês 16 & $9,5 \%$ & $3,5 \%$ & $52,0 \%$ & $-161,6 \%$ & $151,7 \%$ \\
Mês 17 & $12,1 \%$ & $3,2 \%$ & $55,4 \%$ & $-124,9 \%$ & $188,4 \%$ \\
Mês 18 & $12,5 \%$ & $6,5 \%$ & $59,2 \%$ & $-142,6 \%$ & $215,1 \%$ \\
Mês 19 & $8,9 \%$ & $6,9 \%$ & $62,3 \%$ & $-149,7 \%$ & $231,6 \%$ \\
Mês 20 & $7,8 \%$ & $10,0 \%$ & $61,3 \%$ & $-152,9 \%$ & $220,9 \%$ \\
Mês 21 & $8,1 \%$ & $6,7 \%$ & $63,1 \%$ & $-150,8 \%$ & $225,9 \%$ \\
Mês 22 & $7,3 \%$ & $8,8 \%$ & $64,2 \%$ & $-157,7 \%$ & $224,4 \%$ \\
Mês 23 & $7,7 \%$ & $10,7 \%$ & $66,0 \%$ & $-159,7 \%$ & $229,0 \%$ \\
Mês 24 & $6,1 \%$ & $8,8 \%$ & $65,8 \%$ & $-177,0 \%$ & $217,4 \%$ \\
Mês 25 & $5,9 \%$ & $8,9 \%$ & $66,3 \%$ & $-174,3 \%$ & $222,0 \%$ \\
Mês 26 & $2,8 \%$ & $4,8 \%$ & $67,1 \%$ & $-187,7 \%$ & $223,3 \%$ \\
Mês 27 & $4,8 \%$ & $7,1 \%$ & $69,6 \%$ & $-172,1 \%$ & $225,3 \%$ \\
Mês 28 & $5,2 \%$ & $6,2 \%$ & $68,6 \%$ & $-169,9 \%$ & $232,0 \%$ \\
Mês 29 & $3,6 \%$ & $8,4 \%$ & $70,0 \%$ & $-176,8 \%$ & $230,4 \%$ \\
Mês 30 & $1,8 \%$ & $7,9 \%$ & $70,2 \%$ & $-203,4 \%$ & $214,6 \%$ \\
Mês 31 & $1,1 \%$ & $10,8 \%$ & $75,7 \%$ & $-234,9 \%$ & $221,2 \%$ \\
Mês 32 & $0,6 \%$ & $10,0 \%$ & $77,1 \%$ & $-213,2 \%$ & $225,7 \%$ \\
Mês 33 & $1,5 \%$ & $9,7 \%$ & $75,8 \%$ & $-205,0 \%$ & $227,6 \%$ \\
Mês 34 & $1,1 \%$ & $7,0 \%$ & $77,3 \%$ & $-208,4 \%$ & $221,9 \%$ \\
Mês 35 & $-0,7 \%$ & $7,0 \%$ & $77,9 \%$ & $-219,3 \%$ & $211,7 \%$ \\
Mês 36 & $-3,3 \%$ & $4,4 \%$ & $80,6 \%$ & $-233,0 \%$ & $198,8 \%$ \\
\hline & & & & &
\end{tabular}

Fonte: Elaborada pelo autor.

A Figura 2 ilustra a média do RAA em que fica claro que a performance das ações confirma retornos anormais positivos durante a maior parte do tempo, tornando-se negativo após o $33^{\circ}$ mês. 
Figura 2 - Média do RAA (Amostra Completa)

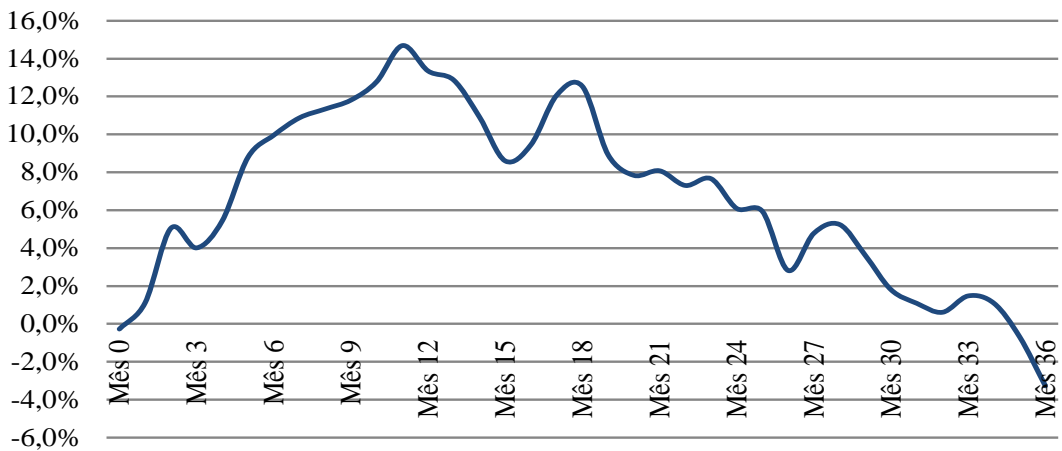

Fonte: Elaborada pelo autor.

A Tabela 4 apresenta o teste $\mathrm{t}$ do Retorno Anormal Acumulado da amostra completa, considerando as 82 empresas. Com base nos resultados, nota-se significância estatística e rejeição da $\mathrm{H}_{0}$ em apenas 10 dos 37 períodos analisados, consecutivamente do período 5 ao 13, inclusive, o que confirmaria a presença de retornos anormais nesses meses, para grau de significância de 5\%. Desta forma, conclui-se que nesse período, foi verificado retorno anormal positivo para as empresas que aderiram aos programas de ADR.

De forma consolidada, considerando o período de 36 meses, não foi encontrada significância estatística no teste $\mathrm{t}$, não sendo possível verificar a presença de retornos anormais. Ou seja, hipótese nula não foi rejeitada no longo prazo, o que confirmaria a hipótese de eficiência semiforte do mercado. 
Tabela 4 - Teste de Hipótese do RAA (Amostra Completa)

\begin{tabular}{l|c|c|c|c|c}
\hline \multicolumn{1}{c|}{ Mês } & Média & t-est & p-value & Significativo & Rejeitar $\mathrm{H}_{0}$ \\
\hline Mês 0 & $-0,3 \%$ & $-0,16$ & 0,871 & não & não \\
Mês 1 & $1,1 \%$ & 0,53 & 0,601 & não & não \\
Mês 2 & $5,0 \%$ & 1,60 & 0,113 & não & não \\
Mês 3 & $4,0 \%$ & 1,19 & 0,239 & não & não \\
Mês 4 & $5,4 \%$ & 1,47 & 0,146 & não & não \\
Mês 5 & $8,8 \%$ & 2,13 & 0,036 & sima 5\% & sim \\
Mês 6 & $10,0 \%$ & 2,36 & 0,020 & sima 5\% & sim \\
Mês 7 & $10,9 \%$ & 2,72 & 0,008 & sima $1 \%$ & sim \\
Mês 8 & $11,3 \%$ & 2,67 & 0,009 & sima 1\% & sim \\
Mês 9 & $11,8 \%$ & 2,59 & 0,011 & sima 5\% & sim \\
Mês 10 & $12,8 \%$ & 2,82 & 0,006 & sima $1 \%$ & sim \\
Mês 11 & $14,7 \%$ & 3,21 & 0,002 & sima $1 \%$ & sim \\
Mês 12 & $13,3 \%$ & 2,83 & 0,006 & sim a $1 \%$ & sim \\
Mês 13 & $12,9 \%$ & 2,84 & 0,006 & sim a $1 \%$ & sim \\
Mês 14 & $10,9 \%$ & 2,30 & 0,024 & sima 5\% & sim \\
Mês 15 & $8,6 \%$ & 1,50 & 0,138 & não & não \\
Mês 16 & $9,5 \%$ & 1,65 & 0,104 & não & não \\
Mês 17 & $12,1 \%$ & 1,97 & 0,052 & não & não \\
Mês 18 & $12,5 \%$ & 1,92 & 0,059 & não & não \\
Mês 19 & $8,9 \%$ & 1,30 & 0,199 & não & não \\
Mês 20 & $7,8 \%$ & 1,16 & 0,250 & não & não \\
Mês 21 & $8,1 \%$ & 1,16 & 0,250 & não & não \\
Mês 22 & $7,3 \%$ & 1,03 & 0,306 & não & não \\
Mês 23 & $7,7 \%$ & 1,05 & 0,296 & não & não \\
Mês 24 & $6,1 \%$ & 0,84 & 0,405 & não & não \\
Mês 25 & $5,9 \%$ & 0,81 & 0,420 & não & não \\
Mês 26 & $2,8 \%$ & 0,38 & 0,705 & não & não \\
Mês 27 & $4,8 \%$ & 0,62 & 0,536 & não & não \\
Mês 28 & $5,2 \%$ & 0,69 & 0,491 & não & não \\
Mês 29 & $3,6 \%$ & 0,47 & 0,641 & não & não \\
Mês 30 & $1,8 \%$ & 0,23 & 0,817 & não & não \\
Mês 31 & $1,1 \%$ & 0,13 & 0,897 & não & não \\
Mês 32 & $0,6 \%$ & 0,07 & 0,943 & não & não \\
Mês 33 & $1,5 \%$ & 0,18 & 0,861 & não & não \\
Mês 34 & $1,1 \%$ & 0,13 & 0,899 & não & não \\
Mês 35 & $-0,7 \%$ & $-0,08$ & 0,936 & não \\
Mês 36 & $-3,3 \%$ & $-0,37$ & 0,714 & não \\
\hline & & & & & \\
\hline
\end{tabular}

Fonte: Elaborada pelo autor.

\subsection{Amostra segregada - Nível I}

Após segregar a amostra dentre os diferentes Níveis de ADR (I, II e III), foram realizadas as mesmas análises verificadas na amostra completa.

Considerando apenas as empresas do Nível I, que representa uma amostra de 39 empresas, cerca de $60 \%$ da amostra total, a média do RA logarítmico ficou negativa em 25 
dos 37 períodos, oscilando do valor máximo de 3,8\% no mês 5 para o valor mínimo de $-6,8 \%$ no mês 15 . O desvio padrão variou de $20,3 \%$ no mês 15 a $10,0 \%$ no mês 8 .

Na Figura 3, ilustra-se a média do RA logarítmico para as empresas componentes dos programas de ADR Nível I, confirmando o retorno negativo na maior parte do tempo, com resultados oscilando em torno de zero.

Figura 3 - Média do RA Logarítmico (Empresas do Nível I)

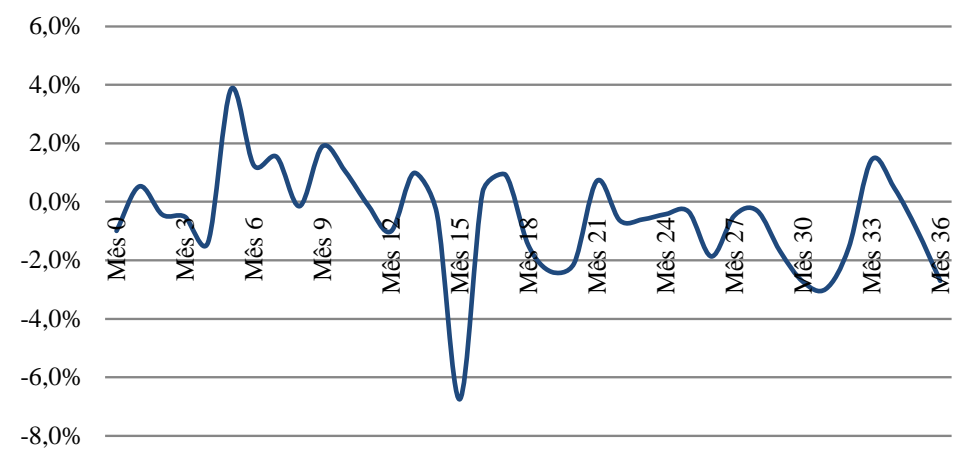

Fonte: Elaborada pelo autor.

Analisando o RAA das empresas do Nível I, nota-se a existência de retorno anormal negativo, acumulado em 20,1\%, com desvio padrão atingindo $85,3 \%$.

A Figura 4 ilustra a média do RAA das empresas do Nível I, onde se percebe uma oscilação bastante relevante. Verifica-se RAA negativo nos quatro primeiros meses após a adesão aos programas de ADR. O retorno anormal acumulado nos meses seguintes, do mês 5 a 13 , torna-se positivo e, novamente, do $15^{\circ}$ mês em diante passa a acumular retornos negativos cada vez maiores.

Figura 4 - Média do RAA (Empresas do Nível I)

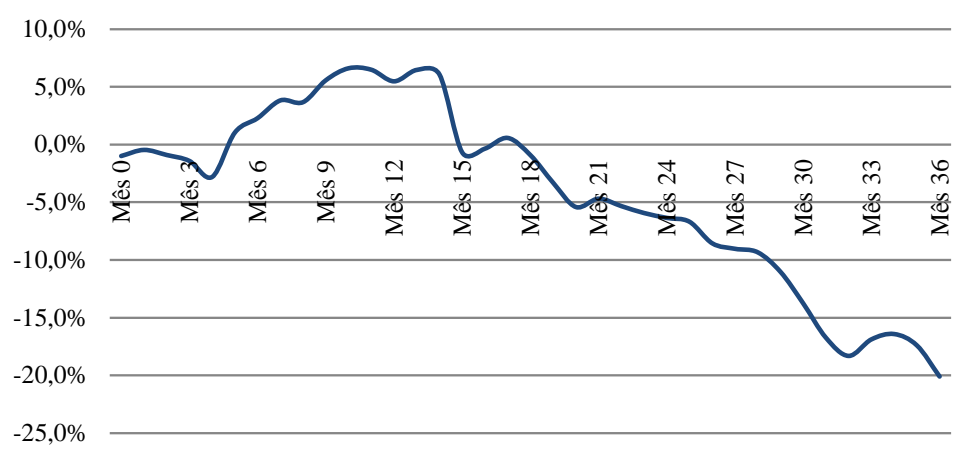

Fonte: Elaborada pelo autor. 
A Tabela 5 apresenta os resultados da análise da amostra composta pelas empresas do Nível I, em que a rejeição da hipótese nula não foi verificada em nenhum período. Este resultado demonstra que para as empresas do Nível I, o retorno anormal acumulado não é estatisticamente significativo no longo prazo. Desta forma, com a não rejeição da $\mathrm{H}_{0}$, é possível concluir pela existência da hipótese de eficiência semiforte do mercado, em função da incorporação do efeito do anúncio da adesão aos programas de ADR sobre os preços das ações das empresas do Nível I.

Tabela 5 - Teste de Hipótese do RAA (Empresas do Nível I)

\begin{tabular}{l|c|c|c|c|c}
\hline \multicolumn{1}{c|}{ Mês } & Média & t-est & p-value & Significativo & Rejeitar $\mathrm{H}_{0}$ \\
\hline Mês 0 & $-1,0 \%$ & $-0,58$ & 0,567 & não & não \\
Mês 1 & $-0,5 \%$ & $-0,18$ & 0,856 & não & não \\
Mês 2 & $-0,9 \%$ & $-0,26$ & 0,796 & não & não \\
Mês 3 & $-1,4 \%$ & $-0,32$ & 0,748 & não & não \\
Mês 4 & $-2,8 \%$ & $-0,63$ & 0,530 & não & não \\
Mês 5 & $1,0 \%$ & 0,21 & 0,835 & não & não \\
Mês 6 & $2,3 \%$ & 0,44 & 0,663 & não & não \\
Mês 7 & $3,8 \%$ & 0,79 & 0,435 & não & não \\
Mês 8 & $3,7 \%$ & 0,74 & 0,465 & não & não \\
Mês 9 & $5,6 \%$ & 1,00 & 0,321 & não & não \\
Mês 10 & $6,6 \%$ & 1,17 & 0,248 & não & não \\
Mês 11 & $6,5 \%$ & 1,15 & 0,255 & não & não \\
Mês 12 & $5,5 \%$ & 0,94 & 0,351 & não & não \\
Mês 13 & $6,5 \%$ & 1,16 & 0,254 & não & não \\
Mês 14 & $6,1 \%$ & 1,02 & 0,313 & não & não \\
Mês 15 & $-0,7 \%$ & $-0,09$ & 0,925 & não & não \\
Mês 16 & $-0,4 \%$ & $-0,05$ & 0,960 & não & não \\
Mês 17 & $0,6 \%$ & 0,08 & 0,936 & não & não \\
Mês 18 & $-0,9 \%$ & $-0,12$ & 0,904 & não & não \\
Mês 19 & $-3,3 \%$ & $-0,40$ & 0,690 & não & não \\
Mês 20 & $-5,4 \%$ & $-0,68$ & 0,497 & não & não \\
Mês 21 & $-4,7 \%$ & $-0,57$ & 0,570 & não & não \\
Mês 22 & $-5,3 \%$ & $-0,60$ & 0,552 & não & não \\
Mês 23 & $-5,9 \%$ & $-0,64$ & 0,526 & não & não \\
Mês 24 & $-6,4 \%$ & $-0,66$ & 0,515 & não & não \\
Mês 25 & $-6,7 \%$ & $-0,68$ & 0,502 & não & não \\
Mês 26 & $-8,6 \%$ & $-0,86$ & 0,396 & não & não \\
Mês 27 & $-9,0 \%$ & $-0,89$ & 0,380 & não & não \\
Mês 28 & $-9,3 \%$ & $-0,92$ & 0,360 & não & não \\
Mês 29 & $-11,0 \%$ & $-1,05$ & 0,298 & não & não \\
Mês 30 & $-13,8 \%$ & $-1,30$ & 0,201 & não & não \\
Mês 31 & $-16,7 \%$ & $-1,44$ & 0,156 & não & não \\
Mês 32 & $-18,3 \%$ & $-1,58$ & 0,121 & não & não \\
Mês 33 & $-16,9 \%$ & $-1,48$ & 0,145 & não & não \\
Mês 34 & $-16,4 \%$ & $-1,41$ & 0,165 & não & não \\
Mês 35 & $-17,4 \%$ & $-1,46$ & 0,150 & não & não \\
Mês 36 & $-20,1 \%$ & $-1,65$ & 0,106 & não & não \\
\hline & & & & &
\end{tabular}

Fonte: Elaborada pelo autor. 


\subsection{Amostra segregada - Nível II}

$\mathrm{Na}$ amostra segregada entre as empresas do Nível II, nota-se que a média mensal do RA logarítmico não apresentou um comportamento uniforme e a presença de retornos anormais foi positiva em 21 dos 37 períodos analisados. $\mathrm{O}$ maior retorno anormal médio foi verificado no mês $2(+13,5 \%)$, enquanto no mês 26 o retorno anormal ficou em $-7,8 \%$, o menor da amostra. O patamar do desvio padrão oscilou entre $22,7 \%$ no mês 0 e $5,7 \%$ no mês 25.

Na Figura 5, é ilustrada a média do RA logarítmico para as empresas componentes dos programas de ADR Nível II, confirmando a forte oscilação da mesma em torno de zero durante todo o período da amostra, com picos nos meses 2, 3, 15 e 27.

Figura 5 - Média do RA Logarítmico (Empresas do Nível II)

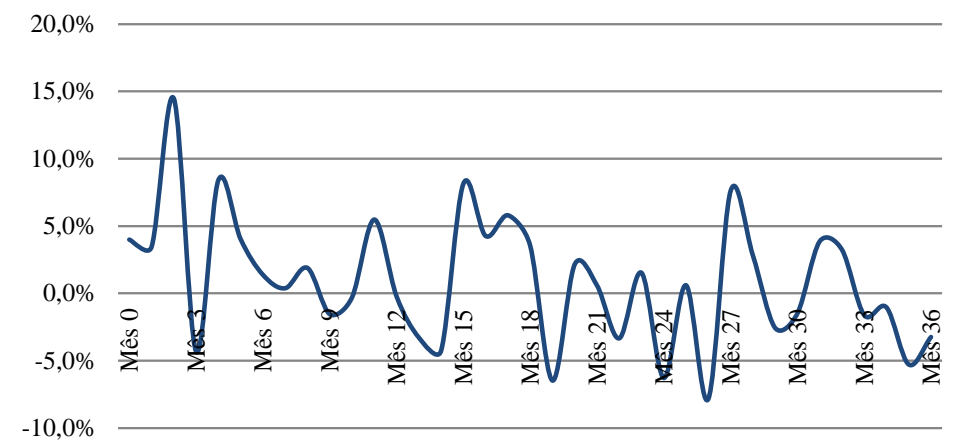

Fonte: Elaborada pelo autor.

Analisando o RAA das empresas do Nível II, a existência de retorno anormal positivo ficou evidente, acumulado em $33,6 \%$ após os 36 meses de análise, com desvio padrão atingindo $68,1 \%$.

A Figura 6 ilustra a média do RAA, confirmando o elevado patamar em todo o período da amostra, atingindo o máximo no mês 18 , em $51,3 \%$, o que explicita a existência de retorno anormal positivo para as empresas do Nível II. 
Figura 6 - Média do RAA (Empresas do Nível II)

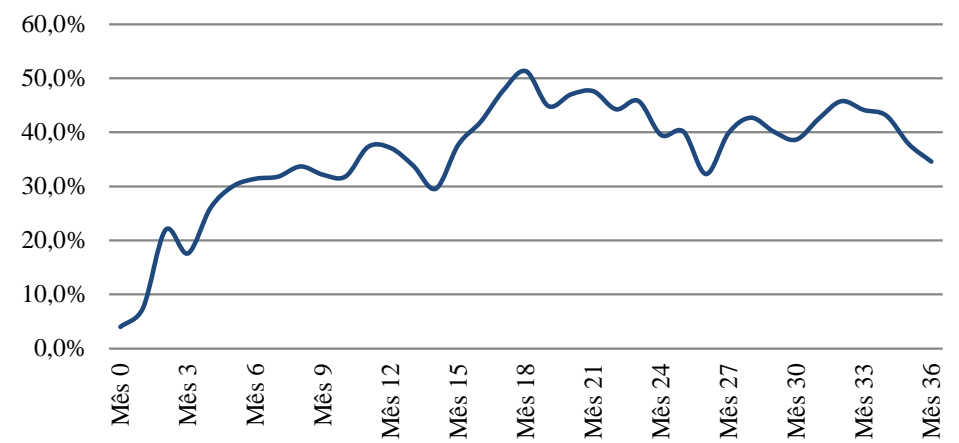

Fonte: Elaborada pelo autor.

A Tabela 6 apresenta o teste t do RAA das empresas do Nível II, onde se nota rejeição da hipótese nula em 35 períodos. A não rejeição da hipótese nula ocorreu apenas nos dois primeiros períodos, dos 37 analisados.

Este resultado demonstra que para as empresas do Nível II, o retorno anormal acumulado se torna, na maior parte do tempo, estatisticamente significativo, o que confirmaria a existência de retorno anormal positivo após a adesão aos programas de ADR, além de eliminar a hipótese de eficiência semiforte do mercado. 
Tabela 6 - Teste de Hipótese do RAA (Empresas do Nível II)

\begin{tabular}{|c|c|c|c|c|c|}
\hline Mês & Média & t-est & p-value & Significativo & Rejeitar $\mathrm{H}_{0}$ \\
\hline Mês 0 & $4,0 \%$ & 0,83 & 0,418 & não & não \\
\hline Mês 1 & $7,4 \%$ & 1,54 & 0,139 & não & não \\
\hline Mês 2 & $21,9 \%$ & 3,10 & 0,005 & sima $1 \%$ & $\operatorname{sim}$ \\
\hline Mês 3 & $17,6 \%$ & 2,70 & 0,013 & sim a $5 \%$ & $\operatorname{sim}$ \\
\hline Mês 4 & $26,0 \%$ & 3,46 & 0,002 & sima $1 \%$ & $\operatorname{sim}$ \\
\hline Mês 5 & $30,0 \%$ & 3,72 & 0,001 & $\operatorname{sim} a 1 \%$ & $\operatorname{sim}$ \\
\hline Mês 6 & $31,4 \%$ & 4,08 & 0,001 & $\operatorname{sim} a 1 \%$ & $\operatorname{sim}$ \\
\hline Mês 7 & $31,8 \%$ & 4,16 & 0,000 & sima $1 \%$ & $\operatorname{sim}$ \\
\hline Mês 8 & $33,7 \%$ & 3,97 & 0,001 & sima $1 \%$ & $\operatorname{sim}$ \\
\hline Mês 9 & $32,1 \%$ & 3,60 & 0,002 & sima $1 \%$ & $\operatorname{sim}$ \\
\hline Mês 10 & $31,8 \%$ & 3,69 & 0,001 & $\operatorname{sim} a 1 \%$ & $\operatorname{sim}$ \\
\hline Mês 11 & $37,3 \%$ & 4,20 & 0,000 & $\operatorname{sim} a 1 \%$ & $\operatorname{sim}$ \\
\hline Mês 12 & $37,1 \%$ & 4,21 & 0,000 & sima $1 \%$ & $\operatorname{sim}$ \\
\hline Mês 13 & $33,8 \%$ & 3,69 & 0,001 & $\operatorname{sim} a 1 \%$ & $\operatorname{sim}$ \\
\hline Mês 14 & $29,6 \%$ & 2,86 & 0,009 & sima $1 \%$ & $\operatorname{sim}$ \\
\hline Mês 15 & $37,7 \%$ & 3,34 & 0,003 & $\operatorname{sim} a 1 \%$ & $\operatorname{sim}$ \\
\hline Mês 16 & $42,0 \%$ & 3,68 & 0,001 & $\operatorname{sim} a 1 \%$ & $\operatorname{sim}$ \\
\hline Mês 17 & $47,8 \%$ & 3,58 & 0,002 & $\operatorname{sim} a 1 \%$ & $\operatorname{sim}$ \\
\hline Mês 18 & $51,3 \%$ & 3,63 & 0,002 & $\operatorname{sim} a 1 \%$ & $\operatorname{sim}$ \\
\hline Mês 19 & $44,8 \%$ & 2,97 & 0,007 & $\operatorname{sim} a 1 \%$ & $\operatorname{sim}$ \\
\hline Mês 20 & $47,0 \%$ & 3,30 & 0,003 & sima $1 \%$ & $\operatorname{sim}$ \\
\hline Mês 21 & $47,6 \%$ & 3,25 & 0,004 & $\operatorname{sim} a 1 \%$ & $\operatorname{sim}$ \\
\hline Mês 22 & $44,3 \%$ & 3,23 & 0,004 & $\operatorname{sim} a 1 \%$ & $\operatorname{sim}$ \\
\hline Mês 23 & $45,8 \%$ & 3,41 & 0,003 & $\operatorname{sim} a 1 \%$ & $\operatorname{sim}$ \\
\hline Mês 24 & $39,5 \%$ & 3,17 & 0,005 & $\operatorname{sim} a 1 \%$ & $\operatorname{sim}$ \\
\hline Mês 25 & $40,1 \%$ & 3,16 & 0,005 & $\operatorname{sim} a 1 \%$ & $\operatorname{sim}$ \\
\hline Mês 26 & $32,3 \%$ & 2,45 & 0,023 & $\operatorname{sim} a 5 \%$ & $\operatorname{sim}$ \\
\hline Mês 27 & $39,9 \%$ & 2,99 & 0,007 & $\operatorname{sim} a 1 \%$ & $\operatorname{sim}$ \\
\hline Mês 28 & $42,7 \%$ & 3,31 & 0,003 & $\operatorname{sim} a 1 \%$ & $\operatorname{sim}$ \\
\hline Mês 29 & $40,1 \%$ & 3,14 & 0,005 & $\operatorname{sim} a 1 \%$ & $\operatorname{sim}$ \\
\hline Mês 30 & $38,6 \%$ & 3,07 & 0,006 & $\operatorname{sim} a 1 \%$ & $\operatorname{sim}$ \\
\hline Mês 31 & $42,5 \%$ & 3,31 & 0,003 & sima $1 \%$ & $\operatorname{sim}$ \\
\hline Mês 32 & $45,8 \%$ & 3,52 & 0,002 & $\operatorname{sim} a 1 \%$ & $\operatorname{sim}$ \\
\hline Mês 33 & $44,1 \%$ & 3,31 & 0,003 & $\operatorname{sim} a 1 \%$ & $\operatorname{sim}$ \\
\hline Mês 34 & $43,1 \%$ & 3,19 & 0,004 & $\operatorname{sim} a 1 \%$ & $\operatorname{sim}$ \\
\hline Mês 35 & $37,8 \%$ & 2,78 & 0,011 & $\operatorname{sim} a 5 \%$ & $\operatorname{sim}$ \\
\hline Mês 36 & $34,6 \%$ & 2,38 & 0,027 & $\operatorname{sim} a 5 \%$ & $\operatorname{sim}$ \\
\hline
\end{tabular}

Fonte: Elaborada pelo autor.

\subsection{Amostra segregada - Nível III}

Para as empresas do Nível III, nota-se comportamento bem similar ao verificado na amostra com empresas do Nível II, com a média mensal do RA logarítmico não apresentando um comportamento uniforme, além da presença de retornos anormais positivos em 20 dos 37 períodos analisados. O maior retorno anormal médio foi verificado no mês 17 
$(+3,8 \%)$, enquanto no mês 0 o retorno anormal ficou em $-5,6 \%$, o menor da amostra. $\mathrm{O}$ patamar do desvio padrão oscilou entre $18,6 \%$ no mês 20 e 3,3\% no mês 3 .

A Figura 7 ilustra o RA médio das empresas do Nível III, mostrando forte oscilação ao redor de 0 , com picos positivos no mês 11,17 e 22 .

Figura 7 - Média do RA Logarítmico (Empresas do Nível III)

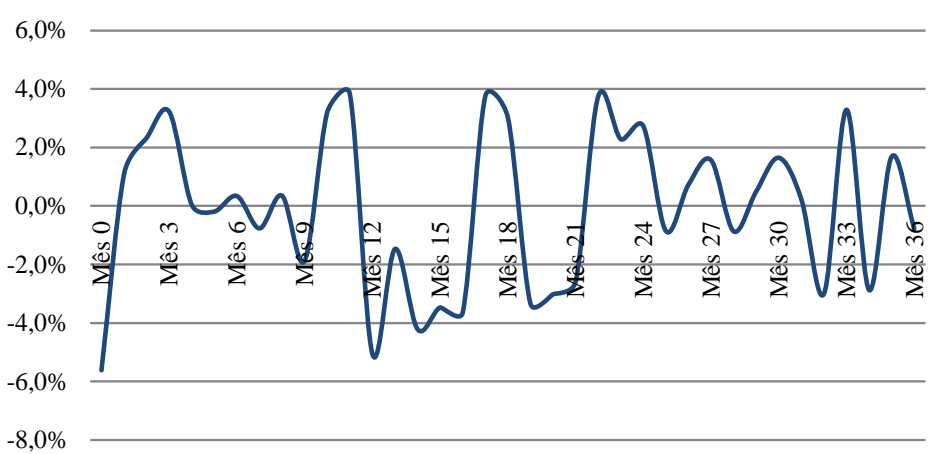

Fonte: Elaborada pelo autor.

O retorno anormal das empresas do Nível III ficou negativo, acumulado em -3,0\% após os 36 meses de análise, com desvio padrão atingindo 57,3\%.

A Figura 8 ilustra a média do RAA, confirmando a relevante oscilação, atingindo o máximo no mês 11 , em $6,0 \%$, mas com a presença de retorno anormal negativo para as empresas do Nível III após 36 meses.

Figura 8 - Média do RAA (Empresas do Nível III)

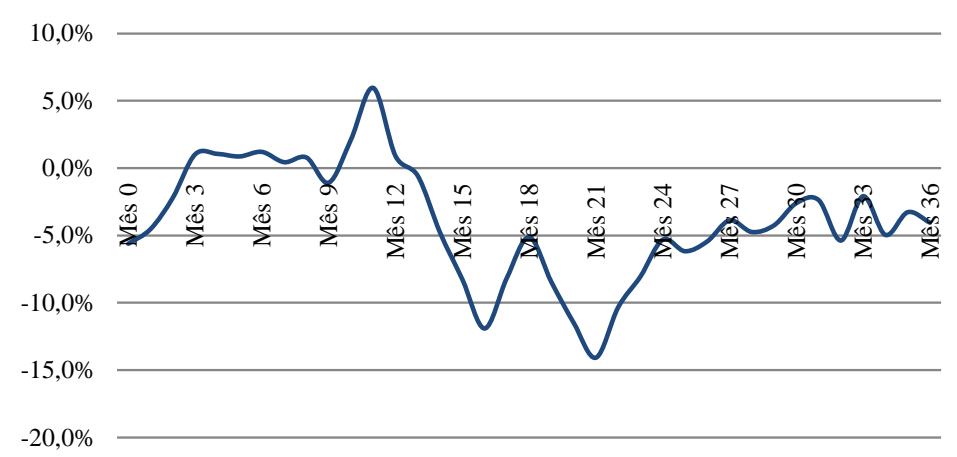

Fonte: Elaborada pelo autor.

A Tabela 7 apresenta o teste $t$ do RAA das empresas do Nível III, onde se observa a rejeição da hipótese nula em apenas um período, no mês 0. Este resultado demonstra que, para as empresas do Nível III, o retorno anormal acumulado se torna estatisticamente 
PUC Minas $\quad$ E\&G - REVISTA ECONOMIA E GESTÃO significativo apenas no momento da divulgação da adesão aos programas de ADR, com retorno negativo em $-5,6 \%$. No restante do período verificado foi confirmada a hipótese de eficiência semiforte do mercado, pela não confirmação de retornos anormais.

Este resultado pode ser justificado pelo fato de haver emissão de novas ações no exterior e, desta forma, ampliar a oferta de ações disponíveis no mercado, reduzindo a demanda pelas ações negociadas na Bolsa brasileira, por estrangeiros, que possam estar migrando para negociar tais títulos na Bolsa local estrangeira.

Tabela 7 - Teste de Hipótese do RAA (Empresas do Nível III)

\begin{tabular}{l|c|c|c|c|c}
\hline \multicolumn{1}{c|}{ Mês } & Média & t-est & p-value & Significativo & Rejeitar $\mathrm{H}_{0}$ \\
\hline Mês 0 & $-5,6 \%$ & $-2,51$ & 0,031 & sima 5\% & sim \\
Mês 1 & $-4,5 \%$ & $-1,01$ & 0,335 & não & não \\
Mês 2 & $-2,2 \%$ & $-0,31$ & 0,766 & não & não \\
Mês 3 & $1,0 \%$ & 0,15 & 0,887 & não & não \\
Mês 4 & $1,1 \%$ & 0,14 & 0,889 & não & não \\
Mês 5 & $0,9 \%$ & 0,09 & 0,933 & não & não \\
Mês 6 & $1,2 \%$ & 0,11 & 0,912 & não & não \\
Mês 7 & $0,4 \%$ & 0,05 & 0,965 & não & não \\
Mês 8 & $0,8 \%$ & 0,07 & 0,943 & não & não \\
Mês 9 & $-1,1 \%$ & $-0,09$ & 0,929 & não & não \\
Mês 10 & $2,1 \%$ & 0,18 & 0,860 & não & não \\
Mês 11 & $6,0 \%$ & 0,55 & 0,597 & não & não \\
Mês 12 & $0,9 \%$ & 0,07 & 0,942 & não & não \\
Mês 13 & $-0,6 \%$ & $-0,06$ & 0,954 & não & não \\
Mês 14 & $-4,8 \%$ & $-0,68$ & 0,511 & não & não \\
Mês 15 & $-8,3 \%$ & $-0,85$ & 0,415 & não & não \\
Mês 16 & $-11,9 \%$ & $-1,32$ & 0,216 & não & não \\
Mês 17 & $-8,2 \%$ & $-0,81$ & 0,439 & não & não \\
Mês 18 & $-5,1 \%$ & $-0,48$ & 0,643 & não & não \\
Mês 19 & $-8,5 \%$ & $-0,90$ & 0,391 & não & não \\
Mês 20 & $-11,5 \%$ & $-0,92$ & 0,380 & não & não \\
Mês 21 & $-14,1 \%$ & $-1,10$ & 0,296 & não & não \\
Mês 22 & $-10,3 \%$ & $-0,79$ & 0,450 & não & não \\
Mês 23 & $-8,0 \%$ & $-0,56$ & 0,588 & não & não \\
Mês 24 & $-5,3 \%$ & $-0,35$ & 0,733 & não & não \\
Mês 25 & $-6,2 \%$ & $-0,50$ & 0,630 & não & não \\
Mês 26 & $-5,4 \%$ & $-0,37$ & 0,717 & não & não \\
Mês 27 & $-3,9 \%$ & $-0,24$ & 0,817 & não & não \\
Mês 28 & $-4,7 \%$ & $-0,33$ & 0,745 & não & não \\
Mês 29 & $-4,2 \%$ & $-0,30$ & 0,768 & não & não \\
Mês 30 & $-2,6 \%$ & $-0,20$ & 0,846 & não & não \\
Mês 31 & $-2,4 \%$ & $-0,19$ & 0,851 & não & não \\
Mês 32 & $-5,4 \%$ & $-0,37$ & 0,718 & não & não \\
Mês 33 & $-2,1 \%$ & $-0,15$ & 0,883 & não & não \\
Mês 34 & $-5,0 \%$ & $-0,32$ & 0,758 & não & não \\
Mês 35 & $-3,3 \%$ & $-0,21$ & 0,839 & não & não \\
Mês 36 & $-4,0 \%$ & $-0,23$ & 0,820 & não & não \\
\hline & & & &
\end{tabular}

Fonte: Elaborada pelo autor. 


\subsection{Amostra segregada - Período de 1992 a 1999}

Finalmente, foram analisados os resultados da amostra segregada pelo período de ocorrência do evento, com duas subdivisões, de 1992 a 1999 e de 2000 a 2009.

Para as empresas do primeiro período, de 1992 a 1999, a média mensal do RA logarítmico não apresentou comportamento uniforme, com a presença de retornos anormais positivos em 17 dos 37 períodos analisados. O maior retorno anormal médio foi verificado no mês $2(+6,8 \%)$, enquanto no mês 26 o retorno anormal ficou em $-6,7 \%$, o menor da amostra. O patamar do desvio padrão oscilou entre $22,3 \%$ no mês 15 e 9,3\% no mês 33 .

A Figura 9 ilustra o RA médio das empresas do período 1992-1999, mostrando forte oscilação ao redor de 0 , com picos positivos no mês 2,17 e 27.

Figura 9 - Média do RA Logarítmico (Empresas do Período de 1992 a 1999)



Fonte: Elaborada pelo autor.

O retorno anormal das empresas do período 1992-1999 ficou negativo, acumulado em 11,3\% após os 36 meses de análise, com desvio padrão atingindo 87,2\%. Após situar-se em patamar positivo do mês 1 ao 25, o RAA ficou negativo no longo prazo.

A Figura 10 ilustra a média do RAA, confirmando a relevante oscilação, atingindo o máximo no mês 11 , em $13,3 \%$, com a presença de retorno anormal negativo para as empresas do período de 1992-1999 após 36 meses. 


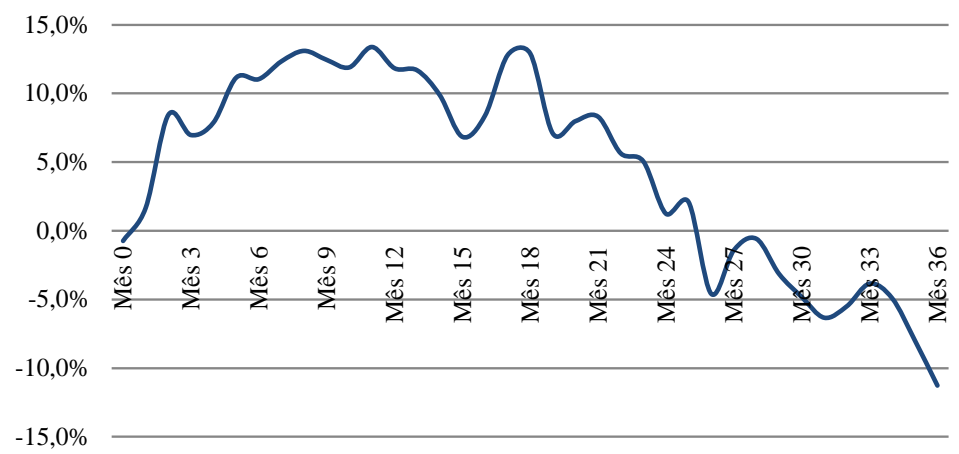

Fonte: Elaborada pelo autor.

A Tabela 8 apresenta o teste t do RAA das empresas do período 1992-1999, onde se observa a rejeição da hipótese nula em apenas dois períodos. Este resultado demonstra que, para as empresas do período 1992-1999, o retorno anormal acumulado se torna estatisticamente significativo apenas nesses dois meses. De forma consolidada, considerando o período de 36 meses, não foi encontrada significância estatística no teste t, não sendo possível verificar a presença de retornos anormais. Ou seja, hipótese nula não foi rejeitada no longo prazo, o que confirmaria a hipótese de eficiência semiforte do mercado. 
Tabela 8 - Teste de Hipótese do RAA (Período de 1992 a 1999)

\begin{tabular}{l|c|c|c|c|c}
\hline Mês & Média & t-est & p-value & Significativo & Rejeitar $\mathrm{H}_{0}$ \\
\hline Mês 0 & $-0,7 \%$ & $-0,27$ & 0,787 & não & não \\
Mês 1 & $1,7 \%$ & 0,55 & 0,585 & não & não \\
Mês 2 & $8,4 \%$ & 1,90 & 0,064 & não & não \\
Mês 3 & $7,0 \%$ & 1,73 & 0,091 & não & não \\
Mês 4 & $7,9 \%$ & 1,56 & 0,126 & não & não \\
Mês 5 & $11,2 \%$ & 1,90 & 0,063 & não & não \\
Mês 6 & $11,0 \%$ & 1,83 & 0,074 & não & não \\
Mês 7 & $12,3 \%$ & 2,29 & 0,027 & sim a 5\% & sim \\
Mês 8 & $13,1 \%$ & 2,24 & 0,030 & sim a 5\% & sim \\
Mês 9 & $12,4 \%$ & 1,99 & 0,052 & não & não \\
Mês 10 & $11,9 \%$ & 1,84 & 0,072 & não & não \\
Mês 11 & $13,4 \%$ & 2,00 & 0,051 & não & não \\
Mês 12 & $11,8 \%$ & 1,72 & 0,092 & não & não \\
Mês 13 & $11,7 \%$ & 1,82 & 0,075 & não & não \\
Mês 14 & $9,9 \%$ & 1,52 & 0,136 & não & não \\
Mês 15 & $6,8 \%$ & 0,79 & 0,432 & não & não \\
Mês 16 & $8,4 \%$ & 0,97 & 0,337 & não & não \\
Mês 17 & $12,8 \%$ & 1,40 & 0,169 & não & não \\
Mês 18 & $12,9 \%$ & 1,30 & 0,201 & não & não \\
Mês 19 & $7,1 \%$ & 0,68 & 0,503 & não & não \\
Mês 20 & $8,0 \%$ & 0,79 & 0,434 & não & não \\
Mês 21 & $8,3 \%$ & 0,80 & 0,429 & não & não \\
Mês 22 & $5,6 \%$ & 0,55 & 0,588 & não & não \\
Mês 23 & $5,1 \%$ & 0,47 & 0,641 & não & não \\
Mês 24 & $1,2 \%$ & 0,12 & 0,904 & não & não \\
Mês 25 & $2,1 \%$ & 0,20 & 0,842 & não & não \\
Mês 26 & $-4,6 \%$ & $-0,44$ & 0,660 & não & não \\
Mês 27 & $-1,4 \%$ & $-0,13$ & 0,899 & não & não \\
Mês 28 & $-0,6 \%$ & $-0,05$ & 0,957 & não & não \\
Mês 29 & $-3,1 \%$ & $-0,28$ & 0,779 & não & não \\
Mês 30 & $-4,8 \%$ & $-0,43$ & 0,668 & não & não \\
Mês 31 & $-6,3 \%$ & $-0,51$ & 0,609 & não & não \\
Mês 32 & $-5,5 \%$ & $-0,44$ & 0,661 & não & não \\
Mês 33 & $-3,9 \%$ & $-0,32$ & 0,750 & não & não \\
Mês 34 & $-4,9 \%$ & $-0,39$ & 0,695 & não & não \\
Mês 35 & $-8,0 \%$ & $-0,65$ & 0,521 & não & não \\
Mês 36 & $-11,3 \%$ & $-0,89$ & 0,380 & não & não \\
\hline & & & &
\end{tabular}

Fonte: Elaborada pelo autor.

\subsection{Amostra segregada - Período de 2000 a 2009}

Para as empresas do segundo período, de 2000 a 2009, a média mensal do RA logarítmico não apresentou comportamento uniforme, com a presença de retornos anormais positivos em 21 dos 37 períodos analisados. O maior retorno anormal médio foi verificado no mês $5(+3,5 \%)$, enquanto no mês 20 o retorno anormal ficou em $-3,8 \%$, o menor da amostra. O patamar do desvio padrão oscilou entre $18,3 \%$ no mês 2 e $7,9 \%$ no mês 36 . 

positivos no mês 5 e 10 .

Figura 11 - Média do RA Logarítmico (Empresas do Período de 2000 a 2009)

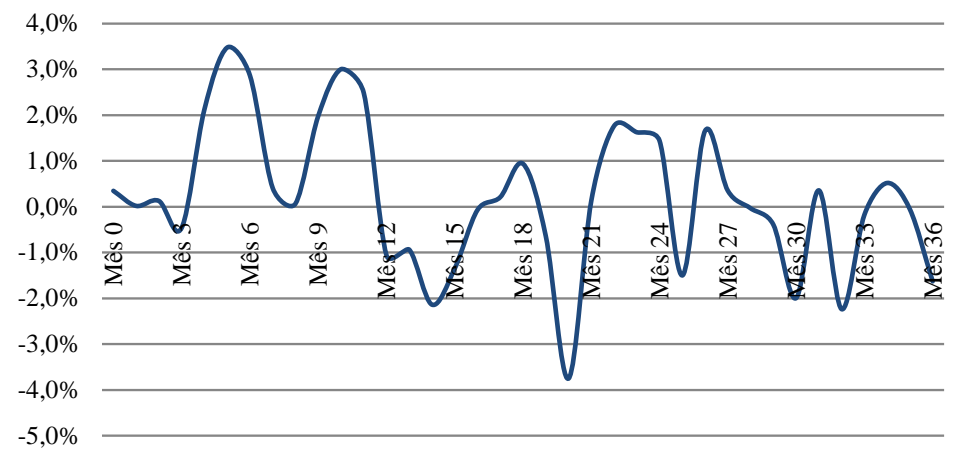

Fonte: Elaborada pelo autor.

O retorno anormal das empresas do período 2000-2009 ficou positivo, acumulado em 7,5\% após os 36 meses de análise, com desvio padrão atingindo 70,3\%. O RAA foi positivo durante todo o período de análise.

A Figura 12 ilustra a média do RAA, atingindo o máximo no mês 11, em 16,3\%, com a presença de retorno anormal positivo para as empresas do período 2000-2009.

Figura 12 - Média do RAA (Empresas do Período de 2000 a 2009)

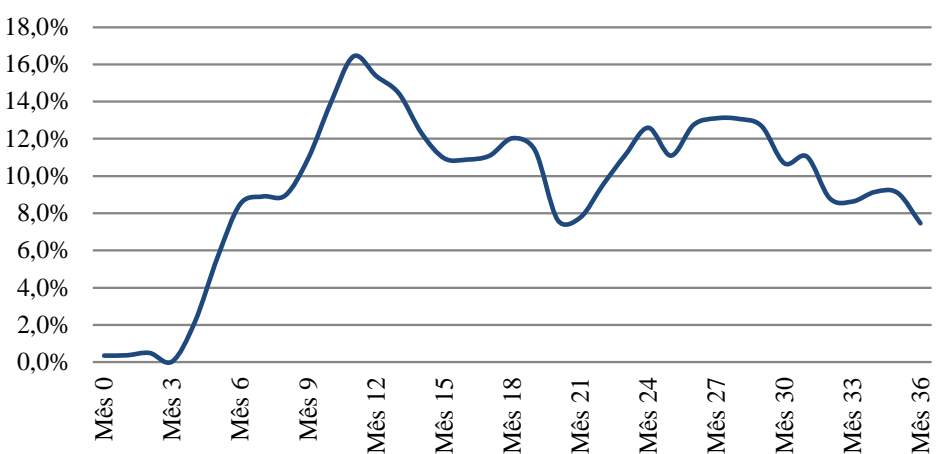

Fonte: Elaborada pelo autor.

A Tabela 9 apresenta o teste t do RAA das empresas do período 2000-2009, onde se observa a rejeição da hipótese nula em apenas quatro períodos. Este resultado demonstra que, para as empresas do período 2000-2009, o retorno anormal acumulado se torna estatisticamente significativo apenas nesses quatro meses, do mês 10 ao 13, inclusive. De forma consolidada, assim como foi verificado para as empresas do primeiro período (1992- 
1999), não foi encontrada significância estatística no teste t, não sendo possível verificar a presença de retornos anormais. Ou seja, hipótese nula não foi rejeitada no longo prazo, o que confirmaria a hipótese de eficiência semiforte do mercado.

Tabela 9 - Teste de Hipótese do RAA (Período de 2000 a 2009)

\begin{tabular}{l|c|c|c|c|c}
\hline Mês & Média & t-est & p-value & Significativo & Rejeitar $\mathrm{H}_{0}$ \\
\hline Mês 0 & $0,3 \%$ & 0,21 & 0,832 & não & não \\
Mês 1 & $0,4 \%$ & 0,13 & 0,900 & não & não \\
Mês 2 & $0,5 \%$ & 0,11 & 0,909 & não & não \\
Mês 3 & $0,0 \%$ & 0,01 & 0,996 & não & não \\
Mês 4 & $2,2 \%$ & 0,39 & 0,696 & não & não \\
Mês 5 & $5,6 \%$ & 1,00 & 0,326 & não & não \\
Mês 6 & $8,5 \%$ & 1,49 & 0,145 & não & não \\
Mês 7 & $8,9 \%$ & 1,48 & 0,148 & não & não \\
Mês 8 & $9,0 \%$ & 1,46 & 0,154 & não & não \\
Mês 9 & $10,9 \%$ & 1,64 & 0,111 & não & não \\
Mês 10 & $13,9 \%$ & 2,26 & 0,030 & sim a 5\% & sim \\
Mês 11 & $16,4 \%$ & 2,74 & 0,010 & sima $1 \%$ & sim \\
Mês 12 & $15,4 \%$ & 2,48 & 0,018 & sima 5\% & sim \\
Mês 13 & $14,4 \%$ & 2,28 & 0,029 & sim a 5\% & sim \\
Mês 14 & $12,3 \%$ & 1,77 & 0,086 & não & não \\
Mês 15 & $11,0 \%$ & 1,58 & 0,124 & não & não \\
Mês 16 & $10,9 \%$ & 1,56 & 0,127 & não & não \\
Mês 17 & $11,1 \%$ & 1,48 & 0,149 & não & não \\
Mês 18 & $12,0 \%$ & 1,57 & 0,125 & não & não \\
Mês 19 & $11,4 \%$ & 1,42 & 0,165 & não & não \\
Mês 20 & $7,6 \%$ & 0,91 & 0,367 & não & não \\
Mês 21 & $7,8 \%$ & 0,90 & 0,374 & não & não \\
Mês 22 & $9,5 \%$ & 1,03 & 0,310 & não & não \\
Mês 23 & $11,2 \%$ & 1,21 & 0,233 & não & não \\
Mês 24 & $12,6 \%$ & 1,25 & 0,220 & não & não \\
Mês 25 & $11,1 \%$ & 1,10 & 0,278 & não & não \\
Mês 26 & $12,8 \%$ & 1,23 & 0,226 & não & não \\
Mês 27 & $13,1 \%$ & 1,28 & 0,208 & não & não \\
Mês 28 & $13,1 \%$ & 1,29 & 0,205 & não & não \\
Mês 29 & $12,7 \%$ & 1,24 & 0,223 & não & não \\
Mês 30 & $10,7 \%$ & 1,05 & 0,303 & não & não \\
Mês 31 & $11,0 \%$ & 1,05 & 0,299 & não & não \\
Mês 32 & $8,8 \%$ & 0,80 & 0,427 & não & não \\
Mês 33 & $8,6 \%$ & 0,77 & 0,448 & não & não \\
Mês 34 & $9,1 \%$ & 0,83 & 0,412 & não \\
Mês 35 & $9,1 \%$ & 0,79 & 0,435 & não \\
Mês 36 & $7,5 \%$ & 0,63 & 0,535 & não & não \\
\hline & & & & &
\end{tabular}

Fonte: Elaborada pelo autor.

\section{Conclusão}

O presente estudo teve como objetivo principal a análise do impacto da dupla listagem sobre o comportamento das ações de empresas brasileiras. Para tal, foi analisada a 
performance de longo prazo por meio do método de Estudo de Eventos das ações de empresas brasileiras listadas na BMFBovespa, emissoras de ADR (Nível I, II ou III) negociados no mercado norte-americano. Foi definida então como hipótese central deste estudo que não é possível notar a presença de retornos anormais dos preços das ações de empresas emissoras de ADRs após o primeiro anúncio do interesse por parte da empresa no lançamento do programa. O esperado neste estudo era que os retornos acumulados médios fossem zero, considerando a hipótese semiforte de eficiência de mercado, onde os preços dos ativos devem refletir e incorporar tanto o histórico como toda informação pública (notícias, comunicados, fatos relevantes, relatórios, resultados etc.) para que o mercado seja considerado eficiente.

Além da análise da presença de retornos anormais da amostra de forma consolidada, foram feitas análises segregadas por Nível de ADR, bem como segregada pelo período de ocorrência do evento (1992-1999 e 2000-2009).

De acordo com Bruni (2002), em função da baixa liquidez dos ativos e do horizonte relativamente curto dos dados disponíveis, é possível utilizar um modelo alternativo, com ajuste ao modelo de mercado, onde o retorno anormal pode ser considerado como aquele superior ao de um portfólio de mercado. Portanto, quanto ao modelo aplicado, a fórmula de cálculo do retorno anormal utilizou o Modelo de Mercado, considerando o $\mathrm{IBrX}$ como proxy para apuração do retorno esperado. Kloeckner (1995) sugere que a adoção de um modelo mais simples para a geração dos retornos normais não acarreta em prejuízos aos resultados.

Entre os resultados aqui encontrados, no que se refere à análise do retorno acionário anormal no longo prazo da amostra consolidada, objetivo central do estudo, não foi encontrada significância estatística para o período de 36 meses. Ou seja, não se pode rejeitar a hipótese nula, constatando-se que a dupla listagem não proporcionou retornos acionários anormais e, por conseguinte, não teve nenhum efeito para os acionistas no mercado brasileiro.

Considerando os resultados das amostras de forma segregada, nota-se divergência dos resultados entre os diferentes níveis de ADR. Para o Nível I, não foi encontrada significância estatística e rejeição da hipótese nula em nenhum período. Para as empresas do Nível II, notou-se significância estatística e rejeição da hipótese nula em 35 dos 37 períodos analisados, com retorno anormal positivo para as ações no mercado local. Já para a amostra das empresas do Nível III, foi observada a rejeição da hipótese nula apenas no período zero, da ocorrência da data do evento, com retorno anormal negativo no curto prazo. Para a análise de longo prazo, não se encontrou significância estatística para as empresas do Nível III. Para 

as empresas segregadas pelo período de ocorrência do evento, o resultado encontrado foi similar nos dois períodos (1992-1999 e 2000-2009), com a rejeição da hipótese nula em poucos períodos da amostra. Ou seja, de forma geral, não se pode rejeitar a hipótese nula no longo prazo, constatando-se que a dupla listagem não proporcionou retornos acionários anormais.

O referencial teórico aqui utilizado, em sua grande maioria, não encontrou retorno anormal acumulado para as ações no mercado doméstico. Camargos e Barbosa (2007) analisaram amostra com 34 empresas emissoras de ADRs I, II e III, concluindo que a dupla listagem não resultou em valorização acionária anormal. Já Neves e Lemes (2008) estudaram os efeitos no retorno sobre as ações de 26 empresas que emitiram ADRs (Nível II e III), não encontrando embasamento estatístico que justifique a valorização das empresas emissoras de ADRs. Para Silva (2010), não foi possível confirmar a valorização acionária de empresas brasileiras que optaram pela dupla listagem.

Por outro lado, Bruni (2002) confirmou a hipótese de retornos anormais com amostra em 43 empresas, considerando ADRs de todos os níveis (I, II e III), em um horizonte de 36 meses. Camargos e Romero (2006) encontraram retornos anormais estatisticamente diferentes de zero no dia do evento, rejeitando-se assim a hipótese nula, o que mostra que o mercado não se comportou de maneira eficiente para a emissão de ADR.

Ainda que não tenha feito parte do escopo do trabalho aqui desenvolvido, a revisão literária realizada permite concluir que, independente da constatação de retornos anormais, existem diversos benefícios atrelados ao processo de dupla listagem, dentre os quais se destacam: (i) redução das barreiras para investidores estrangeiros, reduzindo custos de transação e ampliando o volume de informações; (ii) maior cobertura por parte de especialistas financeiros; (iii) comprometimento com os elevados padrões de Governança Corporativa, que podem contribuir para a redução do custo de capital da companhia; (iv) aumento da liquidez, em função da maior base de acionistas com possibilidade de negociação dos títulos; (v) aumento da visibilidade e reconhecimento da empresa; (vi) benefícios políticos, com eliminação de requisitos de propriedade local; (vii) efeitos positivos aos empregados alocados no exterior, com a possibilidade de negociar as ações de planos de opção de compra e bônus, em bolsa local.

Em função da quantidade limitada de empresas brasileiras com histórico de negociação e informação disponível para períodos longos antes da data do evento, é possível que a utilização de janelas distintas no período de estimação e na janela pós-evento possa 

gerar resultados mais consistentes. Desta forma, como sugestão para trabalhos futuros, montar janelas com períodos curtos na janela de estimação (30,60 ou 90 dias) e períodos longos na janela pós-evento (24 ou 36 meses), com o intuito de ajustar a amostra para contemplar um número maior de empresas, poderá agregar novos resultados aos estudos deste tema no mercado brasileiro. Além disso, a inclusão de empresas participantes dos programas da Regra 144A, não incorporadas neste estudo, poderá ampliar a amostra e gerar novos resultados. 
BOVESPA. IBX Índice Brasil. São Paulo: Bolsa de Valores de São Paulo, 1997.

BROWN, S. J.; WARNER, J. B. Using Daily Stock Returns. Journal of Financial Economics, New York, v. 14, n. 1, p. 3-31, 1985.

BRUNI, A. Globalização financeira, eficiência informacional e custo de capital: uma análise das emissões de ADRS brasileiros no período 1992-2001. 2002. 176 f. Tese (Doutorado em Administração) - Universidade de São Paulo, São Paulo, 2002.

CAMARGOS, M.; BARBOSA, F. Emissão de ADRs, retorno acionário e o comportamento das ações no mercado doméstico: evidências empíricas. Salvador: Anpad, 2006.

CAMARGOS, M.; BARBOSA, F. Criação de valor e impacto na liquidez acionária: evidências empíricas da emissão de American Depositary Receipts. Revista de Administração Eletrônica FEA - USP, São Paulo, v. 1, n. 1, jan. 2007. Disponível em: <http://www.rausp.usp.br/Revista_eletronica/v1n1/artigos/v1n1a5.pdf>. Acesso em: 10 jul. 2012.

CAMARGOS, M.; ROMERO, J. Análise empírica da reação do mercado de capitais brasileiro a eventos corporativos: teste conjunto da hipótese de eficiência do mercado. Revista de Gestão USP, São Paulo, v. 13, n. 3, p. 57-74, 2006.

COMISSÃO DE VALORES MOBILIÁRIOS (CVM). Anexo V. 15 jul. 1992. Disponível em: <www.cvm.gov.br>. Acesso em: 10 dez. 2012.

CORAZZA, G. Globalização financeira: a utopia do mercado e a reinvenção da política. Revista Economia-Ensaios, Uberlândia, v. 19, n. 2, p. 125-140, 2005.

FAMA, E. Efficient Capital Markets: a Review of Theory and Empirical Work. Journal of Finance. Massachusets, v. 25, n. 2, p. 383-417, 1970.

FARIA, José Eduardo. O direito na economia globalizada. São Paulo: Malheiros, 2004. 
FURMANN, Ivan. Globalização e Estado: dimensões e dilemas. Jus Navigandi, Teresina, a. 16, n. 3077, 4 dez. 2011. Disponível em: <http://jus.com.br/revista/texto/20555>. Acesso em: 10 fev. 2013.

GARCIA, P.; GUSMÃO, I. Análise dos custos de transação, das oportunidades de arbitragem e da eficiência de mercado nas empresas brasileiras emissoras de ADR. In: CONGRESSO USP DE CONTROLADORIA E CONTABILIDADE, 5, São Paulo, 2008. Anais... São Paulo, 2008. p. 125-141.

KLOECKNER, G. O. Estudos de evento: a análise de um método. In: ENCONTRO DA ASSOCIAÇÃO NACIONAL DOS PROGRAMAS DE PÓS-GRADUAÇÃO EM ADMINISTRAÇÃO, 19, 1995, João Pessoa. Anais... Rio de Janeiro: Anpad, 1995. p. 261270.

KHOTARI, S. P.; WARNER, Jerold B. Econometrics of Event Studies. Forthcoming. In: ESPEN ECKBO, B. (Ed.), Handbook of Corporate Finance: Empirical Corporate Finance. North-Holland: Elsevier, 2006. Ch. 1. (A Handbooks in Finance Series)

MACKINLAY, C. Event-Studies in Economics and Finance. Journal of Economic Literature, Pennsylvania, v. XXXV, p. 13-39, 1997.

NEVES, L.; LEMES, S. Estudo empírico sobre o comportamento do retorno e da liquidez média das ações no mercado acionário brasileiro das empresas que emitiram ADRs na NYSE e das que aderiram ao novo mercado. 2008. 97 f. Dissertação (Mestrado em Administração de Empresas) - Universidade Federal de Uberlândia, Uberlândia, 2008.

RITTER, J. The Long-Run Performance of Initial Public Offerings. The Journal of Finance, Massachusets, v. 46, n. 1, p. 3-27, 1991.

SETH, A. Sources of Value Creation in Acquisitions: An Empirical Investigation. Strategic Management Journal, Chicago, v. 11, n. 6, p. 431-446, 1990.

SILVA, R. Análise da performance de longo prazo das ações de empresas brasileiras emissoras de ADR. 2010. 75 f. Dissertação (Mestrado em Administração de Empresas) IBMEC, Rio de Janeiro, 2010.

SOARES, R.; ROSTAGNO, L. SOARES, K. Estudo de evento: o método e as formas de cálculo do retorno anormal. In: Encontro Nacional dos Programas de Pós Graduação em Administração - ANPAD, 26, 2002, Salvador. Anais... Salvador: Anpad, 2002. p. 15. 